\title{
Evaluation of Silicone Rubber Insulators used in High-Voltage Transmission Lines
}

\author{
Anwar Ul-Hamid, Khaled Y. Soufi, and Ibrahim Al-Hamoudi
}

(Submitted September 10. 2006; in revised form May 2, 2007)

\begin{abstract}
Three long-rod silicone rubber composite insulators used in $230 \mathrm{kV}$ power transmission lines were evaluated for aging affects. The insulators were obtained from various outdoor desert locations within Saudi Arabia where they had been in service for 6 years. Surface degradation associated with the aging process was analyzed by using Scanning Electron Microscopy (SEM) coupled with Energy Dispersive X-ray Spectroscopy (EDS), Fourier Transform Infra-Red Spectroscopy (FTIR), and Electron Spectroscopy for Chemical Analysis (ESCA). Electrical performance of insulators was evaluated by Rapid Flashover Voltage Tests (RFVT) and Pollution Severity Measurement Tests. Depending on their locations of service, the samples exhibited various types of pollutants at their surfaces. The analysis indicated that the insulator material showed localized surface degradation while there was no evidence of micro-cracking. Furthermore, it was noted that the electrical performance of the insulators was not significantly affected by exposure during the in-service period.
\end{abstract}

Keywords advanced characterization, electron microscopy, material selection, surface engineering

\section{Introduction}

Insulators function against both the operating voltage and the abnormal voltages that are occasionally encountered in the power system. They also support the conductors. The performance of an insulator usually depends on various interrelated factors, such as the quality of raw materials, design, manufacturing technique, and quality control.

Silicone rubber insulators offer a superior electrical performance over their porcelain and glass counterparts for outdoor service (Ref 1 4). They are easy to install and offer superior long-term insulating properties in high-voltage power transmission lines. Advanced performance of silicone insulators is attributed primarily to their ability to retain hydrophobicity and control leakage currents during service in harsh environments (Ref 5). Silicone rubber exhibits the capacity to recover its hydrophobicity even after being stressed and contaminated. This ability assumes greater importance in the climatic conditions of Saudi Arabia, which is characterized by high temperature-humidity regimes. During summer, the temperature rises above $50^{\circ} \mathrm{C}$. In winter, the fast blowing north wind Shamal gives rise to dust storms. In addition, the atmosphere of the Arabian Gulf region is laden with high chloride levels in

Anwar Ul-Hamid and Khaled Y. Soufi, King Fahd University of Petroleum \& Minerals, P.O. Box 1073, Dhahran 31261, Saudi Arabia; and Ibrahim AI-Hamoudi, Saudi Electric Company, Dammam, Saudi Arabia. Contact e-mail: anwarhamid@yahoo.com. coastal regions. Use of silicone insulators in high-voltage transmission lines reduces the need for frequent maintenance, which can be costly and exacting under such conditions.

The insulating property of silicone rubber material is degraded and leakage currents increase when the initially hydrophobic surface becomes hydrophilic due to depletion of low molecular weight (LMW) polymer chains at the surface caused by dry band arcing. However, a temporary discontinuation in dry band arcing can restore the hydrophobicity of the material. This recovery is thought to be due to the diffusion of LMW polymer chains from the bulk of the material to its surface (Ref 3-5); thus imparting a relatively long service life to the silicone insulator. However, permanent changes at the material surface do take place and result in property degradation over time. These changes are represented by depolymerization of the surface in the form of a reduction in the quantity of the LMW polymer chains resulting in increased leakage currents (Ref 5). Degree of roughness and elemental constitution of the polymer surface when correlated with electrical properties of the insulator can help us to determine if the component is fit to remain in service. A measure of these properties can be obtained by SEM/EDS analysis, FTIR, ESCA, and flashover tests.

The aim of this study was to determine the degree of degradation and decomposition of the used silicone rubber insulator material due to outdoor exposure. It involved the study of kind of changes that are associated with the aging process of silicone rubber in so far as these changes are manifested in the top surface layers of the samples by using SEM/EDS, FTIR, and ESCA. It was also intended to evaluate the electrical performance of the insulator and find ways to correlate it with the material's surface condition. This study forms part of a larger investigation that is being conducted in order to determine a viable methodology for evaluating and eventually predicting aging characteristics of silicone rubber insulators currently being used in locations exhibiting wide variety of atmospheric conditions.

Journal of Materials Engineering and Performance 


\section{Experimental Procedure}

\subsection{Test Samples}

Three insulator samples referred to as Sample \#1, Sample \#2, and Sample $\$ 3$ were obtained from three separate locations representing (a) desert-marine, (b) desert, and (c) desertmarine-industrial conditions, respectively. The samples were cleaned with distilled and de-ionized water to remove the atmospheric dust settled over the surface and dried in air.

\subsection{Scanning Electron Microscopy}

Small samples $(10 \times 10 \mathrm{~mm})$ were sectioned from each insulator and their surfaces were analyzed using JEOL 5800LV SEM in low vacuum mode in order to avoid sample charging. Backscattered electron imaging (BEl) was performed to study the surface morphology at an accelerating voltage of $20 \mathrm{kV}$. Elemental analysis was performed using an EDS detector fitted with an ultra-thin window. Silicon to Aluminum ratios were obtained at different accelerating voltages from 3 to $10 \mathrm{kV}$.

\subsection{Fourier Transform Infra-Red Spectroscopy}

Two thin rectangular strips, with dimensions of $50 x$ $10 \times 3 \mathrm{~mm}$, were obtained from the sample. A virgin insulator strip obtained from the central portion of a previous sample was used as reference. Nicolet 20SXB FTIR with deuterated triglycine sulfate (DTGS) detector was used for acquiring the spectra. For this, the routine parameters used for mid-IR range i.e., from 4000 to $400 \mathrm{~cm}^{-1}$ at a resolution of $4 \mathrm{~cm}^{-1}$ were utilized. Attenuated Total Reflectance (ATR) was used with a KRS-5 crystal for sampling.

\subsection{Electron Spectroscopy for Chemical Analysis}

A $10 \times 15 \mathrm{~mm}$ piece was cut from the top surface of each silicone rubber insulator. Each sample was attached to a clean sample holder using copper spring clips and stainless steel serews. ESCA spectra were generated using $\mathrm{K}_{x} \mathrm{x}$-ray radiation from $\mathrm{Mg}$ anode operated at $11 \mathrm{kV}$ and at a power output of 200 watt. The test chamber of the PHI 5300 ESCA System was maintained at a vacuum of less than $2 \times 10^{-8}$ torr during data collection. The samples were not sputtered prior to the generation of ESCA spectra.

\subsection{Rapid Flashover Voltage Test}

The insulators were tested based on IEC 507 (Ref 6) Clean Fog method using the Rapid Flashover Voltage Technique (Ref 7). Each test involved sample preparation, pollution application, and drying. The procedure followed during RFVT is outlined below

Insulator string placed in the fog chamber was energized with a voltage estimated at about $20 \%$ or more above mean flashover value. Steam fog was injected into the fog chamber with a rate of $0.074 \mathrm{~kg} / \mathrm{h}^{3} \mathrm{~m}^{3}$. If no flashover occurred within $25 \mathrm{~min}$, the voltage was increased by $5 \%$ every minute until flashover. After flashover, the insulator was re-energized at a voltage three steps below the last flashover value (one step being $4 \%$ of the test flashover value). The voltage was increased by one step every 3 min until flashover. This sequence was repeated, with FOV values decreasing to a minimum and then gradually rising until they were considerably above the minimum. The performance criterion was the minimum FOV value, which could be defined depending on the wetting time. If it was short, the lowest flashover voltage $\left(V_{\min }\right)$ was used, and if the wetting time was long enough, the minimum of the means of five consecutive FOV values $\left(V_{5}\right.$ min $)$ was used. The RFVT method was evaluated in the HV Lab to check its validity. The test results showed very good agreement between this method and the 'up-and-down' clean fog standard method.

\section{Experimental Results}

\subsection{SEM/EDS Analysis}

A typical insulator assembly is composed of several discshaped sheds attached to a long rod of fiber glass as shown in the schematic diagram and photograph of Fig. 1(a) and (b), respectively. Samples used in this study were obtained from similar insulating sheds. The surface morphology of silicone insulator obtained from sample nos. 1 and 2 appeared predominantly smooth with localized regions of roughness shown as an example in the backscattered SEM image of Fig. 2(a). The difference between the smooth and rough regions is clearly illustrated in the images obtained at a relatively high magnification and shown in Fig. 2(b) and (c), respectively. Smooth region exhibits a fine morphology while the rough region appears to possess coarse features. The roughness can result due to localized degradation of silicone rubber at these regions. Elemental EDS analysis was performed at both regions of each sample and $\mathrm{Si} A \mathrm{Al}$ ratios thus obtained are shown in Table 1. The beam penetration into the sample at $3 \mathrm{kV}$ will be the lowest and will increase with increasing voltage. The $3 \mathrm{kV}$ beam will, therefore, provide elemental information from the top layers of the surface (Ref 5). It can be seen from Table 1 that the $\mathrm{Si}: \mathrm{Al}$ ratio at $3 \mathrm{kV}$ for rough region is lower than the smooth region for both samples 1 and 2 . This implies that LMW polymer chains that are rich in $\mathrm{Si}$ and present at the surface have been consumed due to degradation at the rough areas. As a result, the underlying region with a low Si content is revealed giving off low Si:Al ratio. The depletion of LMW polymer chains allows the contamination at the surface to absorb water and form a thick water film, resulting in a lower surface resistance and higher leakage current.

The Si:Al ratios decrease with increasing beam voltages in a fairly consistent manner for both the rough and smooth regions indicating that $\mathrm{Si}$ content decreases in the bulk of the insulator. Micro-cracking was not observed at the samples' surface.

The insulator sample No. 3 is shown at a low magnification in Fig. 3(a). This sample design comprised of parallel protrusions at its surface at equal intervals. These protrusions were decorated with contaminant particles as evident in Fig. 3(a). It was difficult to remove the contaminants at these areas. The surface morphology, as shown at a higher magnification in Fig. 3(b), appeared to be smooth. Localized regions of roughness were not observed at the sample's surface. The Si:Al ratios were higher compared to sample nos. 1 and 2, especially at the top surface layer i.e., at $3 \mathrm{kV}$. Higher contamination levels at the surface are thought to have contributed to increased Si content observed. The change in $\mathrm{Si}: \mathrm{Al}$ ratios was consistent and agree with the results for previously examined samples. Microcracking was not evident at the surface.

Despite cleaning, pollutants like $\mathrm{S}, \mathrm{Mg}, \mathrm{Na}, \mathrm{Ca}, \mathrm{K}$, and Fe were detected at the insulator surface. However, 


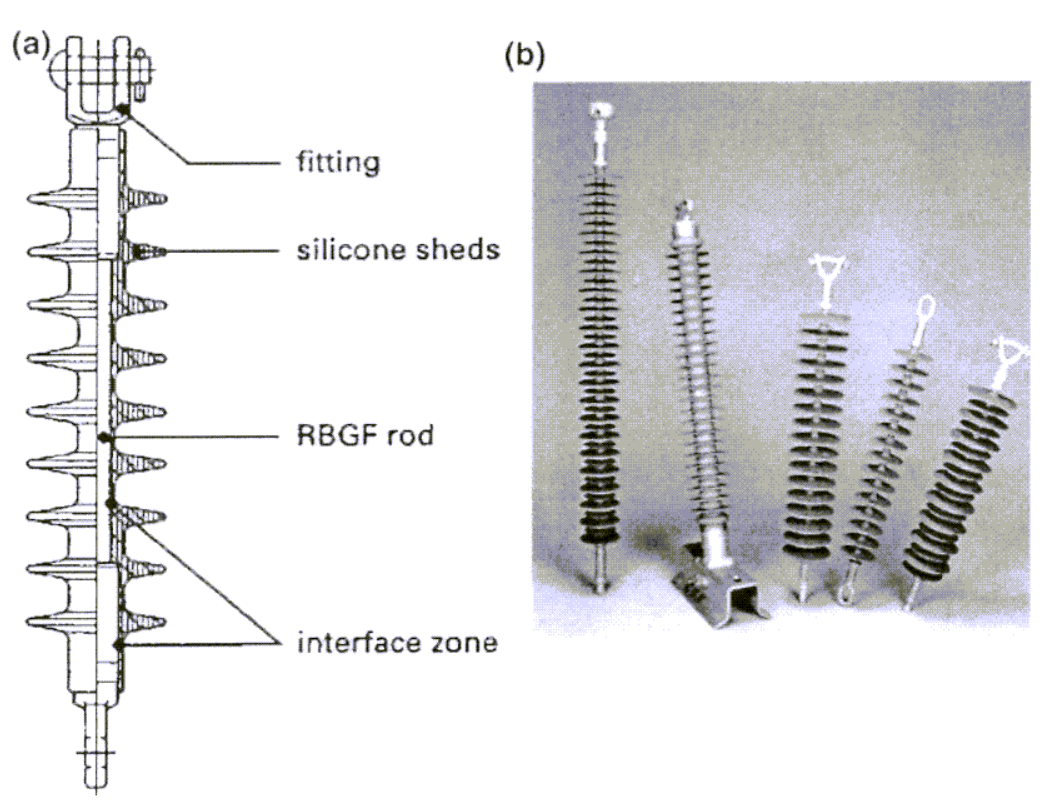

Fig. 1 (a) Schematic illustrating the construction of a typical composite insulator and (b) photograph showing various shapes of composite insulators

SEM/EDS analysis was performed at regions relatively free of contaminants.

\subsection{Fourier Transform Infra-Red Spectroscopy}

The FTIR spectra of all the samples and the reference indicated the typical bands of $\mathrm{C}-\mathrm{H}$ at 2955 to $2960 \mathrm{~cm}^{-1}$, $\mathrm{Si}-\mathrm{CH}_{3}$ at $1260 \mathrm{~cm}^{-1}$, and Si-O-Si at, approximately, $1000 \mathrm{~cm}^{-1}$. The deterioration of the insulator would usually be indicated by the disappearance of the $\mathrm{C}-\mathrm{H}$ and $\mathrm{Si}-\mathrm{C}$ bands at 2960 and $1260 \mathrm{~cm}^{-1}$, respectively. These bands disappear as a result of fragmentation of the carbon-silicon bond in the material. Such fragmentation would result if ultra violet light and oxygen attack the bonds.

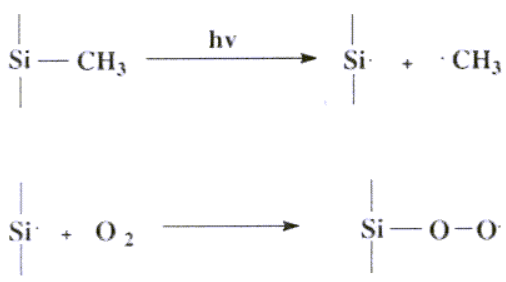

This reaction will eventually lead to a silyl hydroperoxide, which decomposes to the silanol.

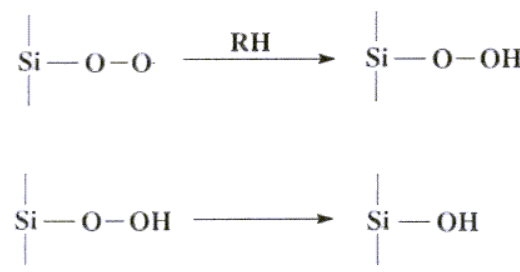

Since such reaction is of free radical nature, it would be expected that the silicone material would lose the methyl groups on the silicon. The material would thus lose its insulating property. If these functional groups were present in any appreciable amounts in the samples they would be observed in the infra-red spectrum.

Sample \#1 showed no IR band at $2960 \mathrm{~cm}^{-1}$. However, the bands at $1260 \mathrm{~cm}^{-1}$ and $1000 \mathrm{~cm}^{-1}$ were as intense as those in the virgin sample. The spectrum of this sample was quite noisy and that could have resulted to the nonobservation of the $2960 \mathrm{~cm}^{-1}$ signal. The spectrum indicates that the sample has not deteriorated to any appreciable extent. The spectrum of this sample is shown in Fig. 4(a).

The infra-red spectrum Fig. 4(b) obtained from sample \#2 showed the expected IR bands at 2960,1260, and $1000 \mathrm{~cm}^{-1}$. These bands when compared to those of the virgin sample indicated that there has not been any deterioration in the material. No IR bands for the $\mathrm{Si}-\mathrm{OH}$ bond was observed. These observations indicated that the silicone sample had not deteriorated to any extent.

Sample \#3 had been exposed to desert, marine, and industrial pollution. The spectrum for this sample showed weak signals for all the bands probably due to an oil film on the sample. The signal at $2960 \mathrm{~cm}^{-1}$ was very weak appearing at exactly $2955 \mathrm{~cm}^{-1}$. The other two bands were prominent. The sample was re-analyzed after thorough cleaning. It was observed that the $2960 \mathrm{~cm}^{-1}$ band had become more intense compared to in the un-washed condition. The FTIR spectrum is shown in Fig. 4(c).

None of the samples appear to have deteriorated to any appreciable extent. The oil film on sample \#3 may serve to protect the insulator against harmful effects of UV light and oxygen.

\subsection{Electron Spectroscopy for Chemical Analysis}

The ESCA survey spectra collected from the samples are exhibited in Fig. 5(a) to (c) and the atomic concentration values are given in Table 2. The survey spectra were not corrected for static charging. The binding energy values of the major features 
in the spectra are given in Table 3. Oxygen, carbon, aluminum, and silicon were detected at the surface layer of the three-aged silicone rubber insulators.
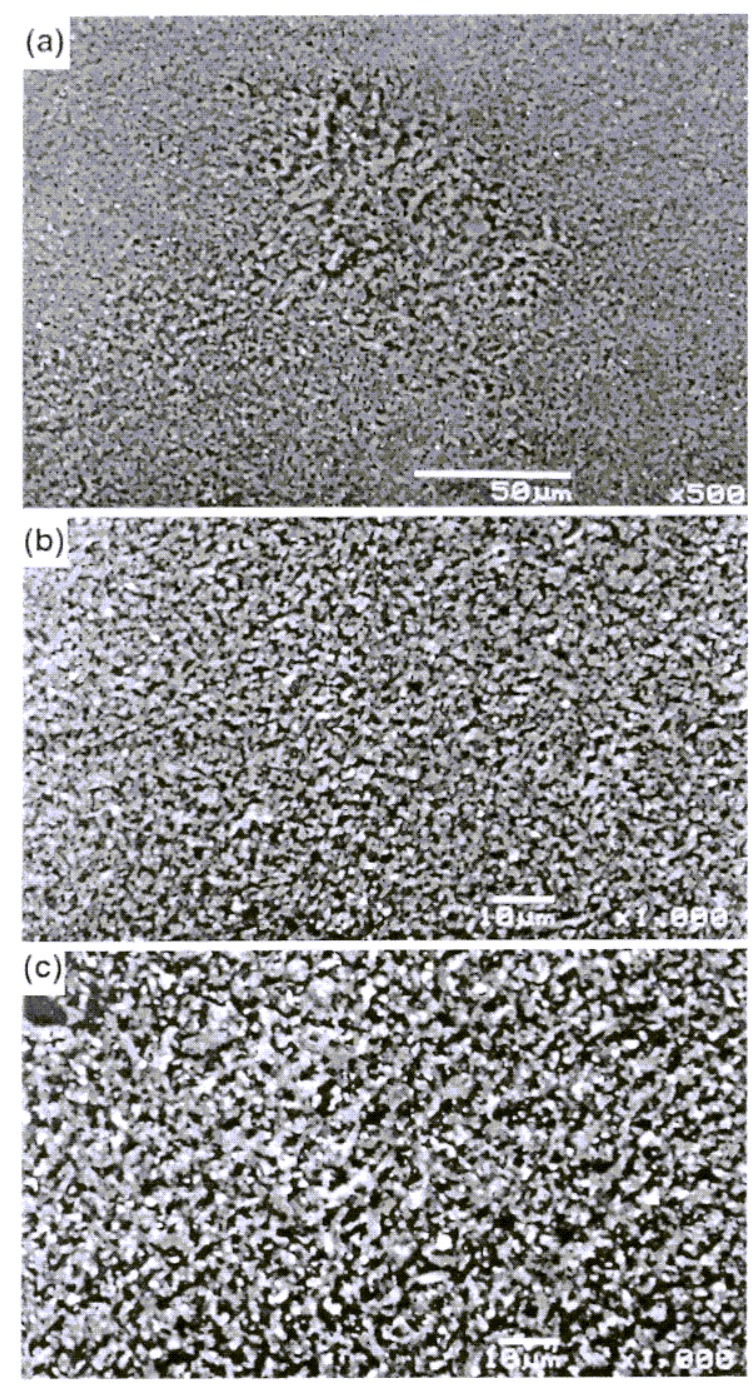

Fig. 2 SEM micrographs obtained from sample \#1 showing (a) an area of localized roughness, (b) smooth region, and (c) rough region
The Si peak at a binding energy of $102.3 \mathrm{eV}$ is due to the silicon in the silicone rubber. Silicon peak at slightly higher binding energy was also observed and is probably due to Si in a hydrous silicate of aluminum, $\mathrm{Al}_{4} \mathrm{Si}_{4} \mathrm{O}_{10}(\mathrm{OH})_{8}$. About $47 \%$ of the surface layer was probably hydrous silicate of aluminum and $53 \%$ silicone rubber.

As reflected in Table 2 , the surface of sample $\# 2$ has the highest amount of silicon and oxygen and the lowest amount of carbon. The silicon to aluminum ratio for this sample, also shown in Table 2, falls between the other two samples. The
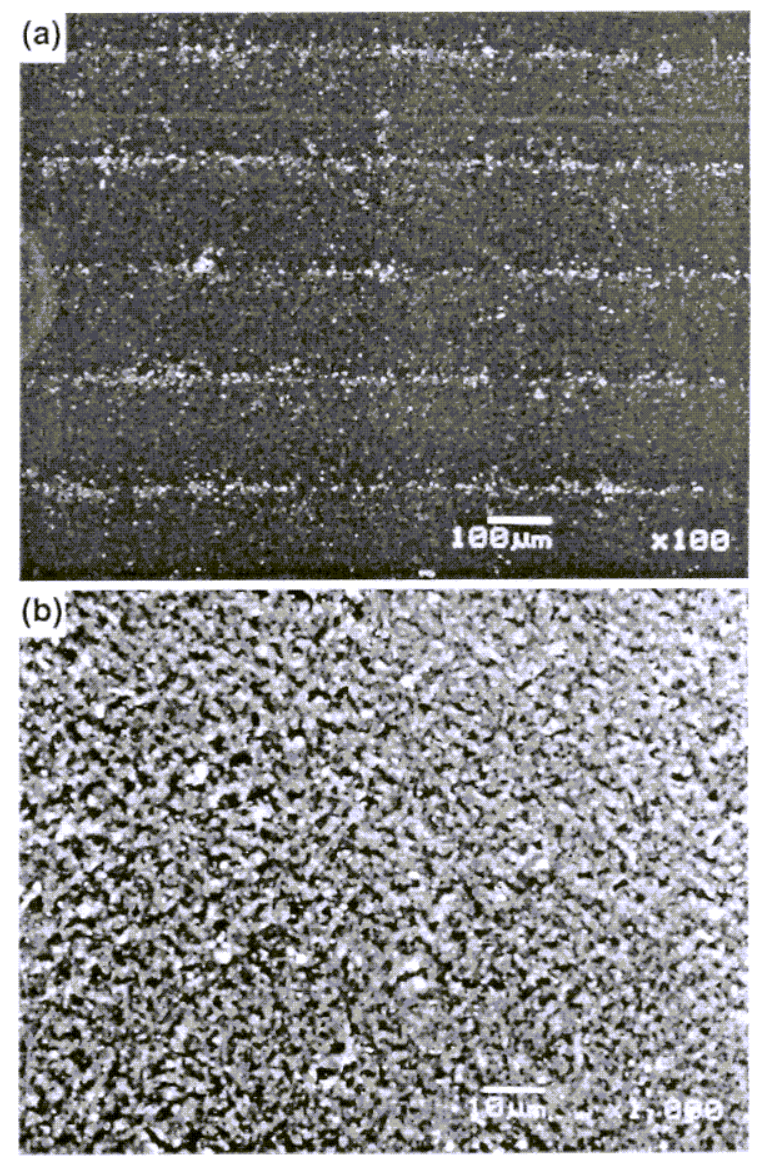

Fig. 3 SEM micrographs obtained from sample \#2 showing morphology of (a) smooth and (b) rough regions

Table 1 SEM/EDS results showing the Si:Al ratios obtained at varying accelerating beam voltages (kV)

\begin{tabular}{|c|c|c|c|c|c|}
\hline \multirow[b]{3}{*}{ Acc. Volt., kV } & \multicolumn{5}{|c|}{ Si:Al ratio } \\
\hline & \multicolumn{2}{|c|}{ Sample \#1 } & \multicolumn{2}{|c|}{ Sample \#2 } & \multirow{2}{*}{$\frac{\text { Sample } \# 3}{\text { General region }}$} \\
\hline & Smooth region & Rough region & Smooth region & Rough region & \\
\hline 3 & $6.75: 1$ & $5.25: 1$ & $7.00: 1$ & $5.93: 1$ & $7.89: 1$ \\
\hline 4 & $7.05: 1$ & $5.22: 1$ & $5.73: 1$ & $7.47: 1$ & $5.14: 1$ \\
\hline 5 & $4.60: 1$ & $4.84: 1$ & $7.08: 1$ & $3.62: 1$ & $3.77: 1$ \\
\hline 6 & $3.17: 1$ & $3.50: 1$ & $5.54: 1$ & $3.66: 1$ & $3.77: 1$ \\
\hline 7 & $2.77: 1$ & $3.60: 1$ & $2.26: 1$ & $3.62: 1$ & $3.54: 1$ \\
\hline 8 & $2.42: 1$ & $2.51: 1$ & $2.66: 1$ & $2.99: 1$ & $2.90: 1$ \\
\hline 9 & $2.03: 1$ & $2.79: 1$ & $2.09: 1$ & $2.89: 1$ & $2.55: 1$ \\
\hline 10 & $1.98: 1$ & $1.82: 1$ & $1.56: 1$ & $2.23: 1$ & $3.15: 1$ \\
\hline
\end{tabular}



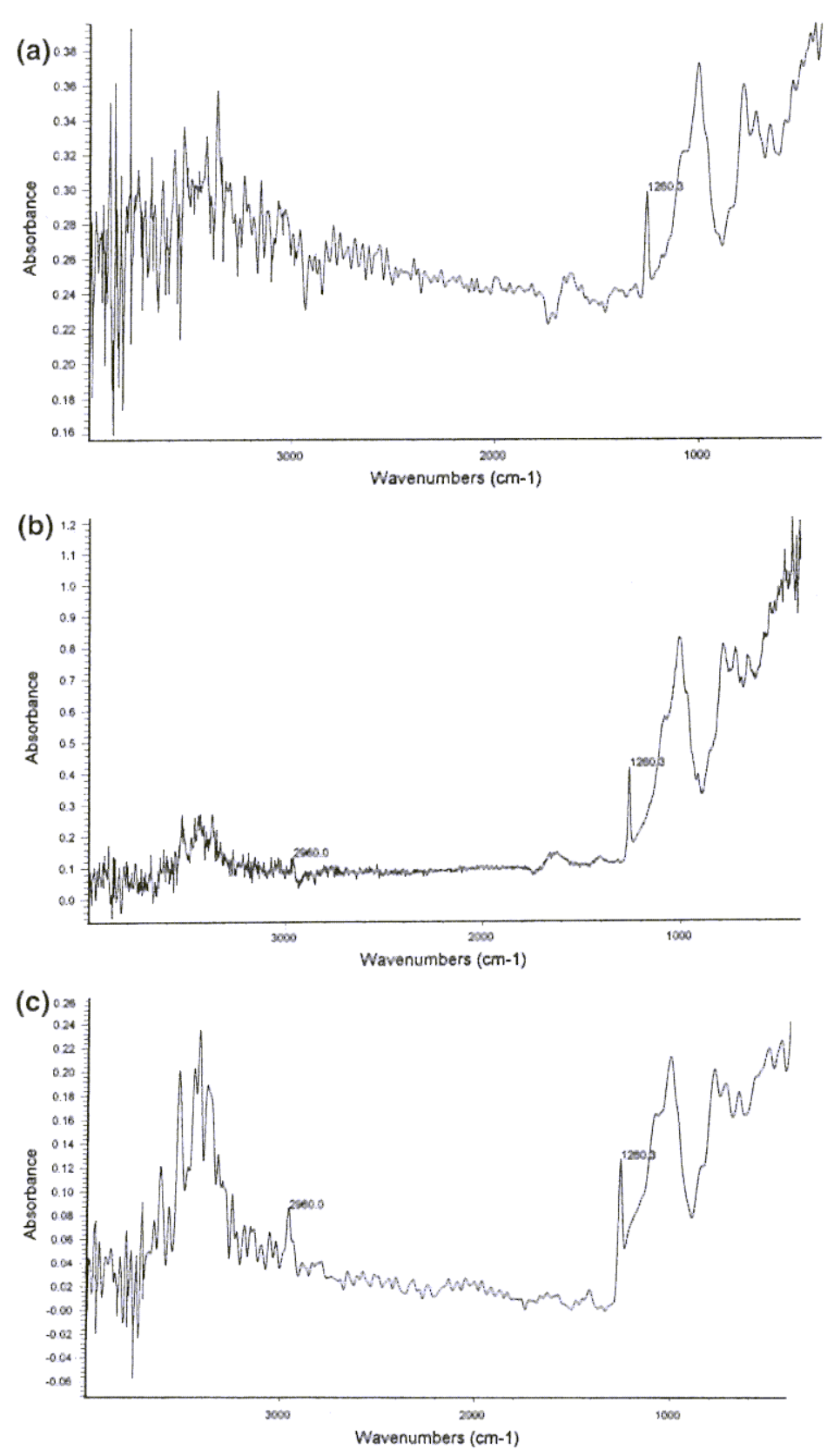

Fig. 4 FTIR spectra obtained from sample nos. (a) 1, (b) 2, and (c) 3

Si:Al ratios are generally favorable for all samples; however, the values will depend on the extent of localized degradation exhibited by the analyzed area.

\subsection{Rapid Flashover Voltage Technique}

To comply with requirements of IEC 507 regarding minimum short-circuit current and according to the limitation of the voltage source of $250 \mathrm{kV}$, each of the three insulators was partially short-circuited.

Eighteen sheds on the bottom high voltage side of sample \#1 were tested at a creepage distance of $201 \mathrm{~cm}$. The results are shown in Fig. 6(a). Equivalent Salt Deposit Density (ESDD) data before and after the test is provided in Table 4. These values indicate the pollution levels at the insulator surface before and after the testing. The $V_{\min }$ of the tested part of this insulator was $154 \mathrm{kV}$. The $V_{\min }$ meter of creepage distance was $76.7 \mathrm{kV}$ as shown in Table 5 .

Fifteen sheds on the bottom high voltage side were tested out of the sheds of sample $\# 2$. The tested creepage distance was $126 \mathrm{~cm}$. Figure 6(b) presents the results of the test run on this sample. The $V_{\min }$ of the tested part of this insulator was $134 \mathrm{kV}$. The $V_{\mathrm{min}} /$ meter of creepage distance was $106.4 \mathrm{kV}$ as shown in Table 5 . 

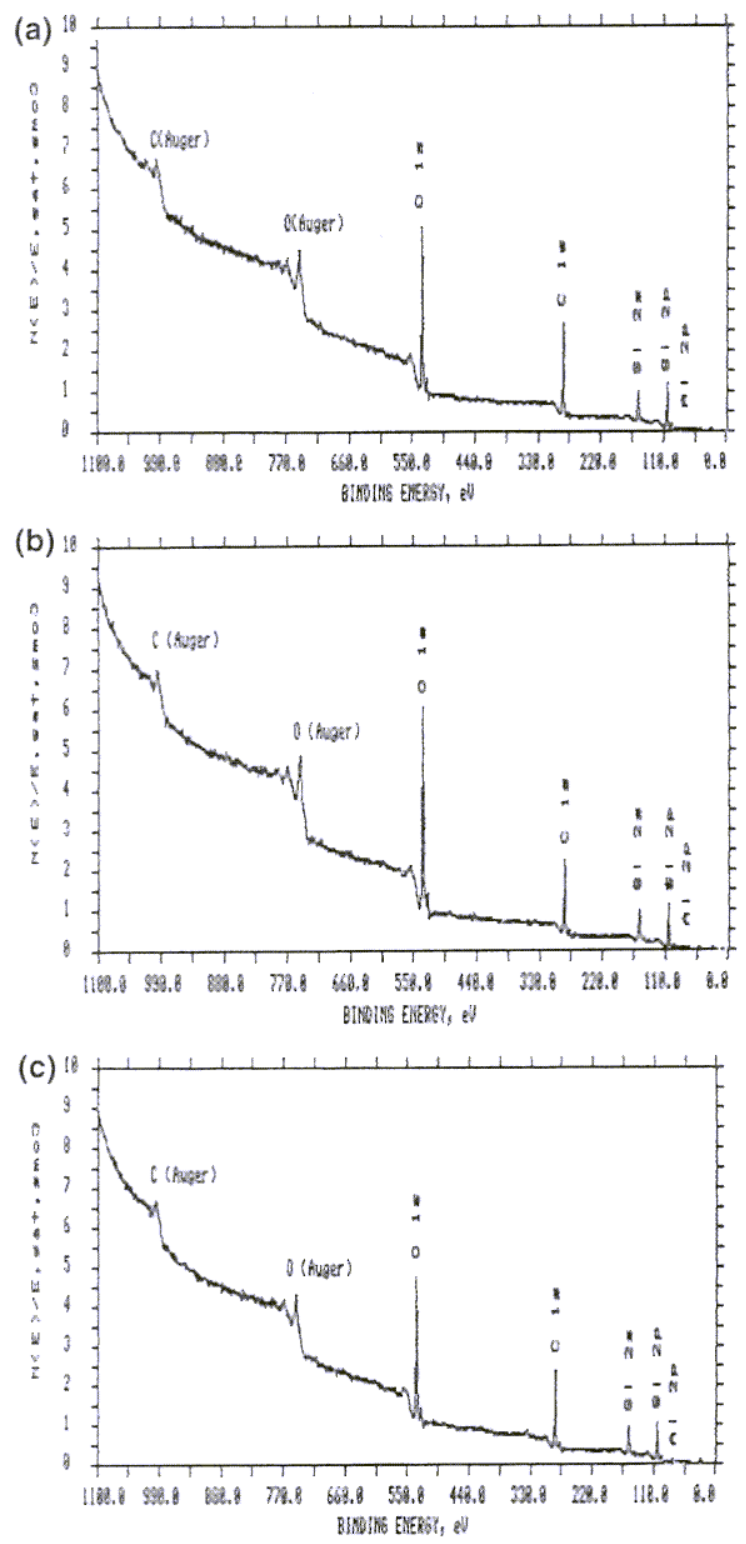

Fig. 5 ESCA survey spectra obtained from samples nos. (a) 1, (b) 2 , and (c) 3

Table 2 ESCA atomic concentration values (in at.\%) and $\mathrm{Si}: \mathrm{Al}$ ratios for three samples

\begin{tabular}{lccc}
\hline & \multicolumn{3}{c}{ Concentration (at.\%)/Si:Al ratio } \\
\cline { 2 - 4 } Elements & Sample \#1 & Sample \#2 & Sample \#3 \\
\hline Oxygen & 26.14 & 36.66 & 22.77 \\
Carbon & 56.82 & 39.95 & 53.56 \\
Aluminum & 0.78 & 2.32 & 8.34 \\
Silicon & 16.27 & 21.07 & 15.33 \\
Si:Al & 20.9 & 9.1 & 1.8 \\
\hline
\end{tabular}

Twelve sheds on the bottom high voltage side of sample \#3 were tested; the creepage distance was $210.5 \mathrm{~cm}$. Figure $6(\mathrm{c})$ presents the results of testing sample $\# 3$. The
Sample \# 1

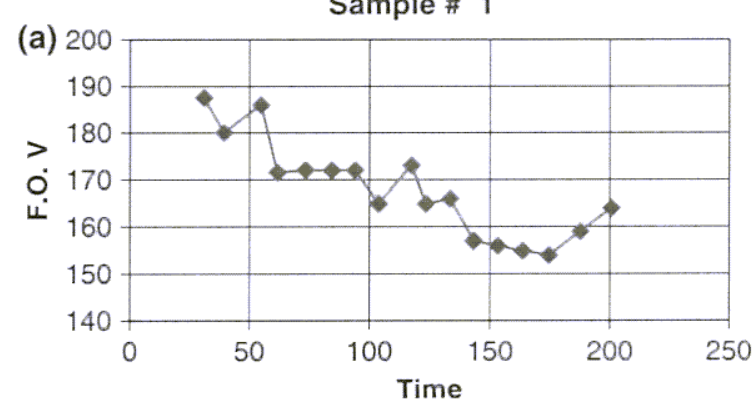

Sample \# 2

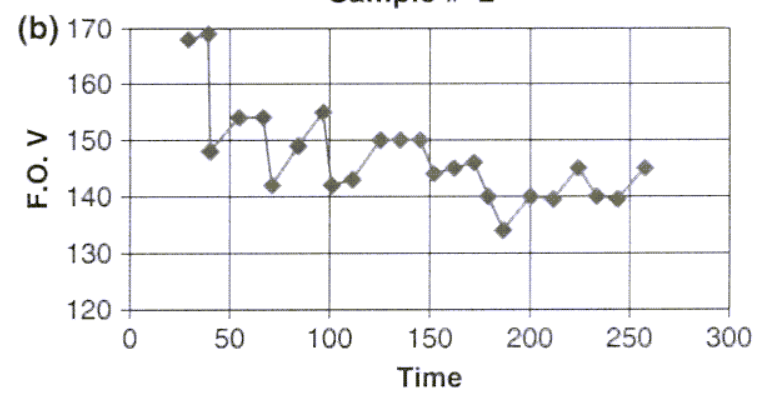

Sample \# 3

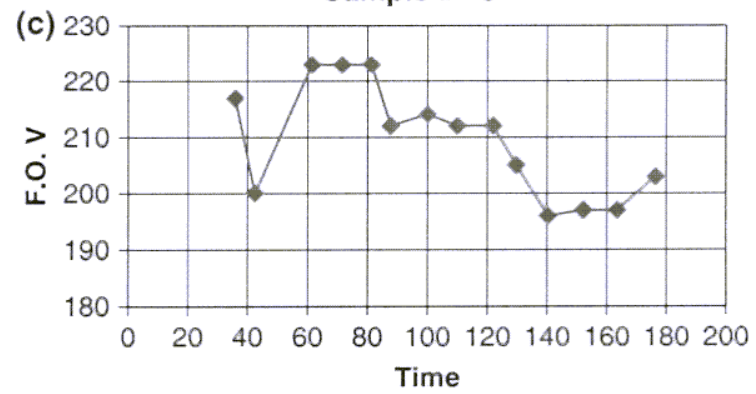

Fig. 6 Plots illustrating the Flashover Voltage tests carried out on naturally polluted insulator sample nos. (a) 1, (b) 2, and (c) 3

Table 3 ESCA binding energy values (eV) of major features in the spectra

\begin{tabular}{lcccc}
\hline Sample nos. & O 1s & C 1s & Al 2p & Si 2p \\
\hline 1 & 532.3 & 284.7 & 74.6 & 102.5 \\
2 & 532.5 & 284.7 & 74.7 & 102.7 \\
3 & 532.4 & 284.7 & 74.8 & 102.3 \\
\hline
\end{tabular}

Table 4 ESDD results before and after the test

\begin{tabular}{lcc}
\hline $\begin{array}{l}\text { Insulator } \\
\text { sample no. }\end{array}$ & $\begin{array}{c}\text { ESDD before } \\
\text { the test, } \mathbf{~} g / \mathrm{cm}^{2}\end{array}$ & $\begin{array}{c}\text { ESDD after } \\
\text { the test, } \mathbf{m g} / \mathrm{cm}^{2}\end{array}$ \\
\hline 1 & 0.290 & 0.236 \\
2 & 0.098 & 0.085 \\
3 & 0.525 & 0.348 \\
\hline
\end{tabular}

$V_{\min }$ of the tested part of this insulator was measured as $196 \mathrm{kV}$. The $V_{\min } /$ meter of creepage distance was $93.12 \mathrm{kV}$ as shown in Table 5. 
Table 5 Results of electrical lab tests

\begin{tabular}{lccc}
\hline $\begin{array}{l}\text { Insulator } \\
\text { sample no. }\end{array}$ & $\begin{array}{c}\text { No. of sheds } \\
\text { tested }\end{array}$ & $\begin{array}{c}\text { Creepage distance } \\
\text { tested, } \mathbf{c m}\end{array}$ & $\begin{array}{c}\boldsymbol{V}_{\min } / \mathrm{m} \text {, } \\
\mathbf{k V} / \mathbf{m}\end{array}$ \\
\hline 1 & 18 & 201 & 76.7 \\
2 & 15 & 126 & 106.4 \\
3 & 12 & 210.5 & 93.12 \\
\hline
\end{tabular}

Above results, compiled in Table 5, indicate that the electrical performance of the insulator samples was satisfactory and they were capable of withstanding high voltages.

\section{Discussion}

Electrical measurements usually determine the ability of a silicone rubber insulator component to remain in service. These measurements are carried out on bulk full-sized samples comprising of Resin Bond Glass Fiber (RBGF) rods with several silicone sheds. In this study, surface analytical techniques including SEM/EDS analysis, FTIR, and ESCA were used in order to find a correlation between the condition of silicone rubber insulator surface and its electrical properties obtained by flashover tests. Such a correlation between the surface degradation and insulating ability of silicone composites can help evaluate their fitness for service by employing techniques in addition to electrical testing. If the extent of surface degradation is examined during the service duration of a component in a given environment, it can be correlated to the level of deterioration in its insulating properties. These techniques also have the advantage of using small shed samples $(\approx 10 \times 10 \mathrm{~mm})$ for analysis.

The experimental results indicate that small isolated regions of roughness were observed at the insulator surface using SEM/EDS while such features were not evident by other surface techniques such as FTIR and ESCA. This is due to the fact that SEM/EDS is a microscopy technique with the ability to scan fine surface areas (in the order of square microns) for imaging as well as chemical analysis. In addition, varying accelerating voltages were used in this SEM study to control the extent of beam penetration into the samples surface. This extraordinary sensitivity to micro-features enabled the observation of fine rough patches at the insulator surfaces using SEM/EDS. Techniques like FTIR and ESCA, although powerful analytical tools in their own right, lack the ability to observe and select micro-areas for analysis. The surface area scanned using these techniques is in the range of square centimeter in size and such scans will not be able to distinguish small isolated rough areas from the general surface. However, as the degree of roughness increases with service and the rough patches increase in dimensions, these techniques prove useful in analyzing the chemistry and chemical bonding within such areas.
In the present study, the samples exhibited only slight roughness which was only detected by SEM/EDS analysis. The flashover tests indicated that the insulating properties of the silicone rubber were intact suggesting that these particular samples were fit for further service. Future monitoring of these samples in service can help correlate the surface degradation of structure with electrical properties.

\section{Conclusions}

Isolated regions $(100-150 \mu \mathrm{m})$ of surface degradation were observed using SEM/EDS technique while such degradation was not evident in FTIR and ESCA results due to the lack of ability of latter techniques to characterize micro-areas. However, none of the samples analyzed in this study exhibited significant deterioration. Localized surface roughness, as observed using SEM/EDS, does not seem to affect the hydrophobicity of the material measured by flashover tests. Therefore the insulator is thought to be fit for use in desert, marine, and industrial environments for extended periods. However, an increase in surface roughness will result in further depletion of LMW polymer chains that can in turn affect the electrical performance of the insulator after prolonged exposure. Continual monitoring of the insulator in service can provide further correlation of surface structure/chemistry and its hydrophobicity.

\section{Acknowledgments}

The authors wish to acknowledge the support of the Research Institute of King Fahd University of Petroleum \& Minerals. Appreciation is extended to Dr. E. Y. Osei-Twum and Mr. M. Romano for assistance in this work. Thanks are also due to Saudi Electric Company for the provision of samples.

\section{References}

1. M. Cojan et al., Polymeric Transmission Insulators: Their Application in France, Italy and the UK, CIGRE, 1980, Paper 22-10

2. R.G. Houlgate et al., Field Experience and Laboratom Research on Composite Insulators for Overhead Lines, CIGRE, 1986, Paper $15-12$

3. A.E. Vlastos and E.M. Sherif, Experience from Insulators with Silicone Rubber Sheds and Shed Coatings, IEEE Trans. Power Deliver, 1989, 4 , Paper Number 89 WM 121-5 PWRD

4. R.S. Gorur, E.A. Cherney, R. Hackam, and T. Orbeck, The Electrical Performance of Polymeric Insulating Materials Under Accelerated Aging in a Fog Chamber, IEEE Trans. Power Deliver. 1988,3, p $1157-1163$

5. R.S. Gorur, G.G. Karady, A. Jagota, M. Shah, A.M. Yates M.A. Green, Aging in Silicone Rubber Used for Outdoor Insulation, IEEE Trans. Power Deliver, 1992, 7(2), p 525-532

6. IEC 507, "Artificial Pollution Test on High Voltage Insulators to be Used on A.C Systems," 1991

7. P. Lambeth, Variable Voltage Application for Insulator Pollution Tests, IEEE PES Summer Mecting. 1987, Paper 87 SM 562-2 